\title{
Importance of Early Treatment in Congenital Hypothyroidism
}

\author{
Khaled Rahmani, ${ }^{1}$ Shahin Yarahmadi, ${ }^{2}$ Koorosh Etemad, ${ }^{3}$ Yadollah Mehrabi, ${ }^{4}$ Nasrin Aghang, ${ }^{5}$ Ahmad \\ Koosha, ${ }^{2}$ and Hamid Soori ${ }^{6,7, *}$ \\ ${ }^{1} \mathrm{PhD}$ student of Epidemiology, Department of Epidemiology, Shahid Beheshti University of Medical Sciences, Tehran, IR Iran \\ ${ }^{2}$ Assistant Professor of Endocrinology, Department of Endocrinology and Metabolism, Ministry of Health, Tehran, IR Iran \\ ${ }^{3}$ Assistant Professor of Epidemiology, Department of Epidemiology, Environmental and Occupational Hazards Control Research Center, School of Public Health, Shahid \\ Beheshti University of Medical Sciences, Tehran, IR Iran \\ ${ }^{4}$ Professor of Biostatistics, Department of Epidemiology, School of Public health, Shahid Beheshti University of Medical Sciences, Tehran, IR Iran \\ ${ }^{5} \mathrm{NCD}$ Expert, Department of Endocrinology and Metabolism, Ministry of Health, Tehran, IR Iran \\ ${ }^{6}$ Safety Promotion and Injury Prevention Research Center, School of Public Health, Shahid Beheshti University of Medical Sciences, Tehran, IR Iran \\ ${ }^{7}$ Professor of Epidemiology, Department of Epidemiology, Shahid Beheshti University of Medical Sciences, Tehran, IR Iran \\ "Corresponding author: Hamid Soori, Professor of Epidemiology, Department of Epidemiology, Shahid Beheshti University of Medical Sciences, Tehran, IR Iran. Tel: \\ +98-2122432040, Fax: +98-2122432040, E-mail: hsoori@yahoo.com
}

Received 2016 October 22; Revised 2016 November 11; Accepted 2017 January 10.

Keywords: Congenital Hypothyroidism, Intelligence Quotient, Early Treatment

\section{Dear Editor,}

Congenital hypothyroidism $(\mathrm{CH})$ is one of the most common endocrine diseases and affects 1 in 1000 to 1 in 4000 newborns worldwide $(1,2)$. The incidence of $\mathrm{CH}$ in Iran is high; 2/1000 newborns (3), and by performing a screening program for congenital hypothyroidism, a total of $\$ 13,078$ was saved per child with $\mathrm{CH}(4)$. According to earlier studies, $\mathrm{CH}$ may have different etiologies in Iran due to a higher rate of transient $\mathrm{CH}(5,6)$. Based on existing evidence, early diagnosis and treatment can prevent the devastating outcome of mental retardation (7). Clinical features of $\mathrm{CH}$ are not evident early in the neonatal period. Newborn screening (NS) for identifying and treating children with $\mathrm{CH}$ is an effective method to deal with this problem. A screening program has been established in Iran since 2004. Based on the national report, the incidence of $\mathrm{CH}$ ranges from 1 in 400 to 1 in 2000 newborns throughout different provinces of Iran (6). Previous studies have shown that when clinical diagnosis and treatment were delayed, the neurodevelopmental prognosis was poor $(8,9)$. Based on earlier research, there is a clear inverse relationship between age at start of treatment and IQ; the worst outcome was observed in children with hypothyroidism who were diagnosed at the ages of 6 and 9 months (10).

We conducted a historical cohort study on children with $\mathrm{CH}$ in Iran. Study subjects consisted of patients with $\mathrm{CH}$ born in 2009 that were 6 years old at the time of the study (2015). A total of 240 children with $\mathrm{CH}$ were randomly selected from national surveillance data, followed prospectively and assessed at the age of 6 years with the Wechsler Intelligence scale for children-revised. To determine the effect of early treatment on the intelligence quotient we divided the children into 2 groups; one group with age at onset of treatment $<20$ days ( 143 children) and another group with age at onset of treatment $\geq 20$ days (97 children). Afterwards, IQ scores in 3 subsets (verbal, nonverbal/performance, and full-scale IQs) were measured in both groups. The independent sample t-test was used to assess the statistical difference between the groups. All analyses were conducted in STATA version 13.

The mean \pm SD of age at start of treatment in all studied subjects was $21.0 \pm 11.3$ days. The results show that 143 (59.6\%) children with $\mathrm{CH}$ treated before 20 days of age had higher mean IQs (102.5 12.9) than those treated after 20 days of age $(99.6 \pm 14.7)$. On the other hand, mean IQs in children with age at onset of treatment before 20 days were approximately 3 scores higher than in the other group. Moreover, in 2 children with $\mathrm{CH}$ that had IQs of 70, treatment had been commenced 22 and 30 days after birth. These results support the importance of early treatment in children with $\mathrm{CH}$.

Based on the study results, we can conclude that it is very important to start treatment in children with congenital hypothyroidism as soon as possible. Although valid scientific resources around the world emphasize on starting treatment in children with $\mathrm{CH}$ before the 28th day (11, 12), the current results illustrate the high importance of starting treatment before day 20. These findings reveal that a delay of even 1 day in starting treatment in children with $\mathrm{CH}$, specifically during the neonatal period (the first 28 days of life), can remarkably decrease the IQs of these children. It can be said that the outcome of $\mathrm{CH}$ depends on the time of initiation of therapy and starting the treatment before 20 days of age has shown to provide the best outcome. We recommend the health policy makers, health managers, and health providers of national new- 
born screenings to consider this important point in the management of children with $\mathrm{CH}$. In summary, we conclude that the therapy should be started without any delay and before 20 days of age or as soon as the diagnosis is made.

\section{References}

1. Chen CY, Lee KT, Lee CT, Lai WT, Huang YB. Epidemiology and clinical characteristics of congenital hypothyroidism in an Asian population: a nationwide population-based study. J Epidemiol. 2013;23(2):85-94. [PubMed: 23291568].

2. Dorreh F, Chaijan PY, Javaheri J, Zeinalzadeh AH. Epidemiology of congenital hypothyroidism in Markazi Province, Iran. J Clin Res Pediatr Endocrinol. 2014;6(2):105-10. doi: 10.4274/Jcrpe.1287. [PubMed: 24932604].

3. Veisani Y, Sayehmiri K, Rezaeian S, Delpisheh A. Congenital hypothyroidism screening program in iran; a systematic review and metaanalysis. Iran J Pediatr. 2014;24(6):665-72. [PubMed: 26019769].

4. Hatam N, Shirvani S, Javanbakht M, Askarian M, Rastegar M. Costutility analysis of neonatal screening program, shiraz university of medical sciences, shiraz, iran, 2010. Iran J Pediatr. 2013;23(5):493-500. [PubMed: 24800006].

5. Karamizadeh Z, Dalili S, Sanei-Far H, Karamifard H, Mohammadi H, Amirhakimi G. Does congenital hypothyroidism have different etiologies in iran?. Iran J Pediatr. 2011;21(2):188-92. [PubMed: 23056786].
6. Rahmani K, Yarahmadi S, Etemad K, Koosha A, Mehrabi Y, Aghang N, et al. Congenital Hypothyroidism: Optimal Initial Dosage and Time of Initiation of Treatment: A Systematic Review. Int J Endocrinol Metab. 2016;14(3):e36080. doi: 10.5812/ijem.36080. [PubMed: 27942261].

7. Ozgelen S, Nijat Bas V, Cetinkaya S, Aycan Z. What has national screening program changed in cases with congenital hypothyroidism?. Iran J Pediatr. 2014;24(3):255-60. [PubMed: 25562017].

8. Chiesa A, Gruneiro de Papendieck L, Keselman A, Heinrich JJ, Bergada C. Growth follow-up in 100 children with congenital hypothyroidism before and during treatment. J Pediatr Endocrinol. 1994;7(3):211-7. [PubMed: 7820215].

9. Hasan MA, Rawabdeh N, El-Majali AJ, Mohaisen M, Dhaiat K. Delayed diagnosis of hypothyroidism in children result in avoidable severe complication: a report of five cases. JRMS. 2003;10(2):48-53.

10. Jacob H, Peters C. Screening, diagnosis and management of congenital hypothyroidism: European Society for Paediatric Endocrinology Consensus Guideline. Arch Dis Child Educ Pract Ed. 2015;100(5):260-3. doi: 10.1136/archdischild-2014-307738. [PubMed: 25776656].

11. Fuggle PW, Grant DB, Smith I, Murphy G. Intelligence, motor skills and behaviour at 5 years in early-treated congenital hypothyroidism. Eur J Pediatr. 1991;150(8):570-4. [PubMed: 1954963].

12. Selva KA, Harper A, Downs A, Blasco PA, Lafranchi SH. Neurodevelopmental outcomes in congenital hypothyroidism: comparison of initial T4 dose and time to reach target T4 and TSH. J Pediatr. 2005;147(6):775-80. doi: 10.1016/j.jpeds.2005.07.024. [PubMed: 16356430]. 